\title{
Diagnóstico da disponibilidade hídrica superficial da bacia hidrográfica do rio Suaçuí-MG e os impactos dos usos insignificantes de água
}

\author{
Diagnosis of the surface water availability of the Suaçuí river basin - MG and the impacts of the \\ insignificant water uses \\ Diagnóstico de la disponibilidad de aguas superficiales de la cuenca del río Suaçuí - MG y de los \\ impactos de los usos insignificantes del agua
}

\author{
Guilherme de Barros Moreira \\ ORCID: https://orcid.org/0000-0002-1271-7434 \\ Universidade Federal de Itajubá, Brasil \\ E-mail: guilherme.marlieria@gmail.com \\ James Lacerda Maia \\ ORCID: https://orcid.org/0000-0001-8792-8722 \\ Universidade Federal de Itajubá, Brasil \\ E-mail: jamesmaia@unifei.edu.br \\ João Paulo Oliveira Silva \\ ORCID: https://orcid.org/0000-0002-2541-7289 \\ Universidade Federal de Itajubá, Brasil \\ E-mail: jpoliveirasilva@unifei.edu.br \\ Eliane Maria Vieira \\ ORCID: https://orcid.org/0000-0003-1749-6105 \\ Universidade Federal de Itajubá, Brasil \\ E-mail: elianevieira@unifei.edu.br
}

\begin{abstract}
Resumo
No estado de Minas Gerais, captações inferiores a 1,0 L/s não precisam ser outorgadas, mas necessitam de um cadastro de uso insignificante. A hipótese deste trabalho é de que esses cadastros para captação de água emitidos em série ao longo de pequenos trechos de um curso de água podem alterar de forma substancial a disponibilidade hídrica do mesmo, e consequentemente, provocar impactos ambientais, bem como propiciar conflitos pelo uso da água. Nesse sentido, o objetivo foi analisar a Política Estadual de Recursos Hídricos de Minas Gerais, no que se refere aos usos insignificantes, contribuindo para o conhecimento das interferências destes usos na disponibilidade hídrica superficial da bacia hidrográfica do rio Suaçuí - MG. Para isso, foi obtida junto ao Instituto Mineiro de Gestão das Águas a relação dos usuários de captação de água superficial do local de estudo. Calculou-se a disponibilidade hídrica da bacia por trechos de cursos d'água, analisando as interferências dos usos insignificantes. Analisando todos os trechos nos quais os usos insignificantes estão presentes, foram constatados que 555 usuários se encontram em situação de indisponibilidade, sendo a maioria destes trechos de pequena extensão, localizados em regiões de cabeceira da área de estudo, e também trechos onde existem duas ou mais captações consideradas insignificantes, ou em trechos consecutivos. Este resultado sugere que a forma como são concedidos os cadastros de usos insignificantes deve ser revista, tomando como base a disponibilidade hídrica do trecho a ser demandado, e não apenas limitado por uma vazão máxima.
\end{abstract}

Palavras-chave: Disponibilidade de trechos; Escassez hídrica; Indisponibilidade hídrica; Outorga.

\begin{abstract}
In the state of Minas Gerais, water abstraction below 1.0 L/s does not need to be authorized, but requires a registration of insignificant use. The hypothesis of this work is that these registrations for water abstraction issued in series along small stretches of a watercourse can substantially alter its water availability, and consequently cause environmental impacts, as well as lead to conflicts over water use. In this sense, the objective was to analyze the Water Resources State Policy of Minas Gerais, regarding the insignificant uses, contributing to the knowledge of the interference of these uses in the surface water availability of the hydrographic basin of the Suaçuí river - MG. For this, the list of surface water users in the study area was obtained from the Instituto Mineiro de Gestão das Águas. The water availability of the basin was calculated by stretches of watercourses, analyzing the interference of insignificant uses. Analyzing all the stretches in which insignificant uses are present, 555 were found to be unavailable, most of these stretches being of small extension, located in headwater regions of the study area, and also stretches where there are two or more catchments considered insignificant, or in consecutive stretches. This result suggests that the way that
\end{abstract}


insignificant use registrations are granted should be revised, taking as a basis the water availability of the stretch to be demanded, and not only limited by a maximum flow.

Keywords: Granting; Stream-to-stream availability; Water scarcity; Water unavailability.

\section{Resumen}

En el estado de Minas Gerais, la captación de agua inferior a 1,0 L/s no necesita licencia, pero requiere un registro de uso insignificante. La hipótesis de este trabajo es que estos registros de extracción de agua emitidos en serie a lo largo de pequeños tramos de un curso de agua pueden alterar sustancialmente su disponibilidad de agua y, en consecuencia, causar impactos ambientales. En este sentido, el objetivo fue analizar la Política Estatal de Recursos Hídricos de MG, en lo que respecta a los usos no significativos, contribuyendo al conocimiento de la interferencia de estos usos sobre la disponibilidad de agua superficial de la cuenca hidrográfica del río Suaçuí - MG. Para ello, se obtuvo del Instituto Mineiro de Gestão das Águas la lista de usuarios de aguas superficiales en el área de estudio. La disponibilidad hídrica de la cuenca se calculó por tramos de cursos de agua, analizando la interferencia de los usos no significativos. Analizando todos los tramos en los que están presentes los aprovechamientos insignificantes, se ha comprobado que 555 se encuentran en situación de indisponibilidad, siendo la mayoría de estos tramos de pequeña extensión, situados en regiones de cabecera de la zona de estudio, y también tramos en los que hay dos o más captaciones consideradas insignificantes, o en tramos consecutivos. Este resultado sugiere que se revise la forma de otorgar las inscripciones de uso insignificante, tomando como base la disponibilidad de agua del tramo a demandar, y no sólo limitada por un caudal máximo.

Palabras clave: Concesión; Disponibilidad de agua por tramo; Escasez de agua; Indisponibilidad de agua.

\section{Introdução}

$\mathrm{O}$ acelerado desenvolvimento econômico está relacionado ao consumo de água. $\mathrm{O}$ aumento pela demanda desse recurso natural vem ocasionando problemas de acesso em quantidade e qualidade adequadas em várias partes do planeta, o que destaca a importância da efetiva gestão das águas.

Vilar (2014) aponta que os problemas relacionados à governança dos recursos hídricos induzem ao risco de crise hídrica e de conflitos pelo uso de água, e que tal governança pode incluir outros atores, além dos já estabelecidos no desempenho das funções políticas.

Os conflitos pelo uso das águas estão relacionados a critérios subjetivos ou evidências de escassez do recurso. A carência de informações que relacionem a disponibilidade hídrica com os dados de vazões já outorgadas, pode ser um dos motivos para que ocorra um conflito de uso de água; esta deficiência está diretamente ligada à falta de planejamento e gerenciamento dos recursos hídricos (Moreira et al., 2012).

Segundo Levy e Sidel (2011), a gestão dos recursos hídricos é uma necessidade iminente, devendo ter como premissa o objetivo de adequar as demandas econômicas, sociais e ambientais por água em níveis sustentáveis, de modo a permitir, sem conflitos, a convivência dos usos atuais e futuros do recurso.

No Brasil, a Lei Federal n 9.433, de 8 de janeiro de 1997, que instituiu a Política Nacional de Recursos Hídricos (Brasil, 1997), trouxe seis instrumentos para a gestão dos recursos hídricos, dentre os quais, está a outorga de direitos de uso de recursos hídricos, que objetiva assegurar o controle quantitativo e qualitativo dos usos da água e o efetivo exercício dos direitos de acesso.

A outorga das águas é um mecanismo de racionalização dos recursos hídricos, impondo prioridades para os seus diferentes usos, protegendo o abastecimento humano em períodos de escassez, assim como a vazão necessária à preservação do ecossistema aquático (Medeiros, 2000).

Segundo Carrera-Fernandez e Garrido (2002), a outorga de direito de uso dos recursos hídricos tem caráter disciplinador e racionalizador do uso deste recurso, compatibilizando-o com a disponibilidade hídrica da bacia. Já Cruz (2001) coloca os objetivos da outorga de forma mais abrangente, inclusive no sentido de prioridade de uso: "esse instrumento tem como objetivo racionalizar e compatibilizar a conservação ambiental e os diferentes usos da água, de tal forma que sejam preservados os direitos dos usuários, priorizando entre estes o abastecimento público”. 
A expansão da variedade de usos da água, resultante do crescimento populacional e do desenvolvimento industrial e econômico, aliado também às mudanças e alterações ambientais que ocorrem de forma natural, e que vem paulatinamente sendo agravadas e acrescidas pela ação antrópica, levam à redução da disponibilidade hídrica, podendo originar a ocorrência de situações conflitantes pelo uso da água (Mendes, 2007; Levy \& Sidel, 2011). Neste cenário, o instrumento de outorga dos recursos hídricos mostra-se ainda mais relevante, no sentido de minimizar conflitos entre usuários, garantindo a preservação dos recursos hídricos.

Vários tipos de usos e intervenções em recursos hídricos, como derivações, captações e lançamentos, estão sujeitos a outorga. A Lei Federal n 9.433/1997 dispensa de outorga os usos dos recursos hídricos para satisfação de pequenos núcleos populacionais, distribuídos no meio rural, e as derivações, captações, lançamentos e acumulações de água consideradas insignificantes (Brasil, 1997).

No Estado de Minas Gerais, a Lei Estadual n 13.199, de 29 de janeiro de 1999, que instituiu a Política Estadual de Recursos Hídricos (Minas Gerais, 1999), também estabeleceu a outorga pelo poder público dos direitos de uso dos recursos hídricos como um de seus instrumentos, em analogia à Lei Federal, inclusive no que se refere aos usos que independem de outorga. Na legislação estadual, a outorga é concebida como o instrumento de controle dos usos dos recursos hídricos que visa assegurar o uso racional e a minimização dos impactos ambientais.

O Decreto Estadual n 41.578, de 8 de março de 2001, que regulamenta a Lei Estadual n 13.199/1999 (Minas Gerais, 2001), estabelece que a dispensa de outorga de uso para as acumulações, derivações ou captações e os lançamentos considerados insignificantes e para satisfação das necessidades de pequenos núcleos populacionais, respeitará os critérios e demais parâmetros normativos fixados pelos Comitês de Bacia Hidrográfica (CBH's), compatibilizados com as definições de vazão remanescente e vazão de referência definidas nos respectivos Planos Diretores.

O estabelecimento dos critérios e parâmetros normativos pelos CBH's deve ser precedido de estudos e proposta técnica a serem realizados pelas respectivas agências e, na sua falta, pelo Instituto Mineiro de Gestão das Águas (Igam), desde que previamente autorizado pelo Conselho Estadual de Recursos Hídricos - CERH (Minas Gerais, 2001).

Desta forma, em 16 de junho de 2004, foi publicada a Deliberação Normativa CERH n 09 (CERH, 2004), a qual estabelece as definições dos usos insignificantes para as circunscrições hidrográficas em Minas Gerais e, desde então, não houve nenhuma atualização ou revisão dos valores fixados e da metodologia aplicada na definição, seja pelo Igam ou pelos CBH's.

Nesse sentido, a disponibilidade hídrica é a informação primordial que fundamenta a análise e decisão sobre a outorga de direito de uso dos recursos hídricos para determinado curso d'água, e assim assegura o controle quantitativo e qualitativo dos usos da água e o efetivo exercício dos direitos de acesso à água, conforme disposto na Lei Federal nº 9.433 (Brasil, 1997).

A outorga de recursos hídricos tem sido a temática crescente de diversos trabalhos, considerando os inúmeros desafios encontrados no campo teórico, prático e operacional dos sistemas de gestão e emissão de outorgas. Os trabalhos desenvolvidos geralmente se propõem ao aprimoramento do gerenciamento das demandas e disponibilidades hídricas, amparados pela adoção de metodologias e estratégias de gestão e alocação de água, com objetivo de suprir todas as necessidades de uso, evitando conflitos nas bacias (Stinghen \& Mannich, 2019).

Silva et al. (2015) avaliaram os índices de conflito pelo uso da água na gestão e no planejamento de recursos hídricos da bacia hidrográfica do rio Paraopeba, visando identificar potenciais conflitos pelo uso da água e fornecer subsídios às ações do órgão gestor de recursos hídricos do Estado de Minas Gerais. No cálculo dos índices, além do modelo digital de elevação para a obtenção das áreas de drenagem da foz de cada um dos segmentos, foram necessários os valores das vazões outorgadas e das vazões estimadas nas confluências da hidrografia da bacia.

Os resultados do cálculo mostraram que em $22,7 \%$ dos segmentos analisados o total das vazões outorgadas são 
superiores às estimativas das vazões permitidas, indicando uma potencial situação de conflito pelo uso da água. Além disso, os autores verificaram que em três segmentos as vazões outorgadas superaram a vazão média de longa duração. A análise efetuada permitiu concluir que, em eventuais conflitos pelo uso da água, a solução pode ser obtida com a adoção de políticas públicas ou investimentos em obras de engenharia que aumentem a disponibilidade de água para outorga ao longo do ano (Silva, Silva e Moreira, 2015).

Os autores Duarte e Miola (2016) avaliaram se a quantidade de outorgas concedidas para uso dos recursos hídricos na microbacia do Ribeirão Paciência, no município de Pará de Minas, resultava em uma pressão excessiva no manancial, além de averiguar se o volume de água da microbacia seria suficiente para manter o equilíbrio entre oferta e demanda referentes às outorgas concedidas. Após serem feitos os levantamentos em relação à disponibilidade hídrica da bacia, os autores concluíram que na área de estudo havia equilíbrio entre oferta e demanda. Entretanto, destacam que o aumento populacional, o crescimento industrial e a escassez de investimentos ambientais podem ocasionar pressão sobre os recursos hídricos.

Castro et al. (2021) analisaram a disponibilidade hídrica superficial na bacia hidrográfica do rio Piracicaba (MG) utilizando a metodologia para elaboração do Zoneamento Ambiental Produtivo - ZAP (Faria et al., 2016). Na pesquisa foram realizados cálculos de disponibilidade hídrica trecho a trecho da área estudada, além de calcular a viabilidade de regularização de vazão dos trechos classificados com indisponibilidade hídrica. Nos resultados, os autores identificaram 103 trechos com indisponibilidade hídrica na bacia hidrográfica, sendo que desses trechos, apenas em 3 não há viabilidade de regularização de vazão. Os autores destacaram que a informação de disponibilidade hídrica da área do estudo deve ser mantida atualizada, no intuito de obter um melhor cenário para auxiliar as decisões no âmbito da gestão hídrica da bacia do rio Piracicaba.

Utilizando a mesma metodologia (ZAP), Salis (2017) avaliou e espacializou a disponibilidade e demanda hídrica superficial na bacia hidrográfica do rio Manso, na região metropolitana de Belo Horizonte. Foram identificados na bacia 215 pontos de captação de água superficial com processos de outorga vigentes. Estes representavam uma demanda de $0,1831 \mathrm{~m}^{3} / \mathrm{s}$ associada a 15 usos distintos, sendo os principais: irrigação, consumo humano, dessedentação de animais, aquicultura, mineração e lavagem de veículos. Embora a maior parte do curso d'água esteja em estado de disponibilidade hídrica, alguns pontos apresentaram-se em estado de atenção, apontando a necessidade de uma análise integrada da bacia, de forma a garantir a sua sustentabilidade.

No que tange a disponibilidade hídrica e concessão de outorga, os tipos de usos dos recursos hídricos a serem outorgados e aqueles que podem ser dispensados de outorga variam de acordo com o corpo hídrico e o órgão gestor. Os usos insignificantes de água são estabelecidos quando a vazão captada é menor que a definida em legislação como a mínima para se obter a solicitação da outorga por parte do usuário.

Como exemplo, no Estado do Paraná, segundo a Resolução 39/2004 (Secretaria de Estado do Meio Ambiente e Recursos Hídricos, 2004), é dispensada a outorga de captações individuais, ou lançamentos de efluentes em corpos d'água com vazão inferior ou igual a $1,8 \mathrm{~m} / \mathrm{h}$, equivalente a $0,5 \mathrm{~L} / \mathrm{s}$. Além disso, o somatório das captações insignificantes deve ser menor do que $20 \%$ da vazão outorgável no corpo hídrico. Caso contrário, qualquer nova interferência na disponibilidade do corpo hídrico fica sujeita aos procedimentos de outorga.

Em corpos d'água de domínio estadual, especificamente em Minas Gerais, essa regra não existe, constituindo uma das justificativas que embasam este trabalho, considerando que o efeito cumulativo de várias captações superficiais insignificantes por um mesmo usuário pode interferir substancialmente na disponibilidade hídrica do manancial.

A classificação como insignificante não exclui a responsabilidade do órgão gestor em computar e quantificar esses usuários nos balanços hídricos quali-quantitativos, uma vez que um conjunto de usos insignificantes pode tornar-se significativo (Silva \& Monteiro, 2003). Portanto, o cadastramento dos usos considerados insignificantes, além dos usos outorgáveis, é de extrema importância, pois, principalmente em bacias em estado de escassez hídrica, os usos considerados 
"insignificantes", se considerados numa macrovisão, podem ocasionar um impacto negativo sobre a disponibilidade hídrica, não garantindo a oferta entre os múltiplos usos.

Nesse contexto, Stinghen e Mannich (2019) realizaram um diagnóstico para identificar e quantificar os tipos de usos que recebem outorgas e dispensas de outorga por seus usos insignificantes no Estado do Paraná. O enfoque dado na avaliação foram os impactos gerados por usuários cadastrados e dispensados de outorgas em pequenas bacias hidrográficas. A análise da influência dos usos considerados insignificantes em relação à vazão outorgável em bacias de pequeno porte no Estado revelou que a contribuição é inferior a 3\%, em média. Os autores concluíram, então, que a gestão dos recursos hídricos no Paraná está adequada em relação ao tratamento dos usos insignificantes, não representando uma ameaça à disponibilidade dos recursos hídricos neste Estado.

Cabe salientar que o estudo desenvolvido por Stinghen e Mannich (2019) utilizou a metodologia de análise da disponibilidade hídrica versus demanda a nível de bacia hidrográfica. Diferentemente, neste trabalho, será incluída a análise da disponibilidade hídrica por trechos de cursos d'água, considerando as vazões retiradas pelas outorgas e cadastros de usos insignificantes.

Marcolini (2016) identificou uma deficiência de estudos que avaliem as interferências provocadas pelos usos dispensados de outorgas em bacias de pequeno porte. O autor verificou que a vazão do ribeirão Água Fria em Palmas (TO) não está suportando a demanda de captações autorizadas pelo órgão ambiental (usos outorgados e usos insignificantes), juntamente com as captações sem autorização, sendo essas captações superiores à disponibilidade hídrica do ribeirão, provocando conflitos de escassez de água.

A cada ano cresce o número de demandas de fiscalização sobre conflitos pelo uso da água recebidas no órgão ambiental estadual de Minas Gerais (SEMAD, 2019), as quais abordam principalmente os usos considerados insignificantes. Por exemplo, é comum e permitido, atualmente, a obtenção pelo mesmo usuário, ou usuários diferentes, de diversos cadastros de usos insignificantes para captação de água superficial em um curso d’água, relativamente próximos entre si (em série), prática que determinados usuários tem usado como alternativa para não se enquadrarem na modalidade de outorga, propriamente dita (Igam, 2019).

Ainda conforme a Portaria Igam n 48/2019, para obtenção do cadastro de uso insignificante o usuário deve preencher um formulário específico, informando as coordenadas geográficas do uso do recurso hídrico, vazão, finalidade e modo de uso, entre outras informações gerais. Portanto, não é necessária a apresentação de estudos técnicos e hidrológicos que demonstrem a capacidade de determinado curso de água ofertar uma vazão específica, bem como as vazões residuais. Dessa forma, cadastros de usos insignificantes para captação de água superficial emitidos em série ao longo de pequenos trechos de um curso d'água podem ter capacidade de alterar de forma substancial o regime, quantidade e qualidade do mesmo, e consequentemente, provocar impactos ambientais, bem como propiciar conflitos pelo uso da água e não garantir a oferta entre os múltiplos usos, hipótese esta que é objeto de estudo nesta pesquisa.

Consoante a isso, a identificação da relação entre as demandas, as atividades associadas aos usos em uma bacia, e a disponibilidade de água para supri-las, são fundamentais para o estabelecimento de um bom diagnóstico de recursos hídricos que fornecerá suporte à gestão da água.

Assim, se mostra de grande relevância o estudo da disponibilidade hídrica de uma bacia hidrográfica, tendo em vista a análise dos impactos e interferências dos usos definidos como insignificantes na DN CERH n 09/2004. Para isso, adotou-se como área de estudo neste trabalho a circunscrição hidrográfica do rio Suaçuí (CH DO4), escolhida por se tratar de um território com vocação predominantemente agropecuarista, com alta demanda de água por irrigação e, principalmente, por ter entrado em estado crítico de escassez hídrica nos últimos anos, conforme as Portarias Igam nº 36/2015 (Igam, 2015), 38/2017 (Igam, 2017), 23/2018 (Igam, 2018), 25/2019 (Igam, 2019) e 43/2021 (Igam, 2021). 
Nesse sentido, o objetivo geral deste estudo foi analisar a Política Estadual de Recursos Hídricos de Minas Gerais, especialmente no que se refere à regulamentação dos usos insignificantes de águas superficiais na circunscrição hidrográfica do rio Suaçuí.

\section{Metodologia}

\subsection{Caracterização do estudo}

Este estudo pode ser caracterizado quanto à dois aspectos (Pereira et al., 2018):

- Abordagem: pesquisa quantitativa. Nesse tipo de estudo, emprega-se métodos quantitativos para obtenção e análise dos dados, envolvendo estatísticas, métodos numéricos, equações matemáticas, entre outros; e

- Métodos: estudo de caso. Por sua vez, nesse tipo de pesquisa, são descritos e analisados, de forma detalhada, fenômenos, acontecimentos e eventos específicos, no intuito de explorar e investigar as causas, consequências e características particulares dos mesmos.

\subsection{Caracterização da área de estudo}

A Circunscrição Hidrográfica do rio Suaçuí (CH DO4) insere-se totalmente no Estado de Minas Gerais. Ocupa área de $21.555 \mathrm{~km}^{2}$, constituindo-se a maior unidade da bacia hidrográfica do rio Doce, em termos de área (Figura 1).

Figura 1 - Delimitação da CH DO4.

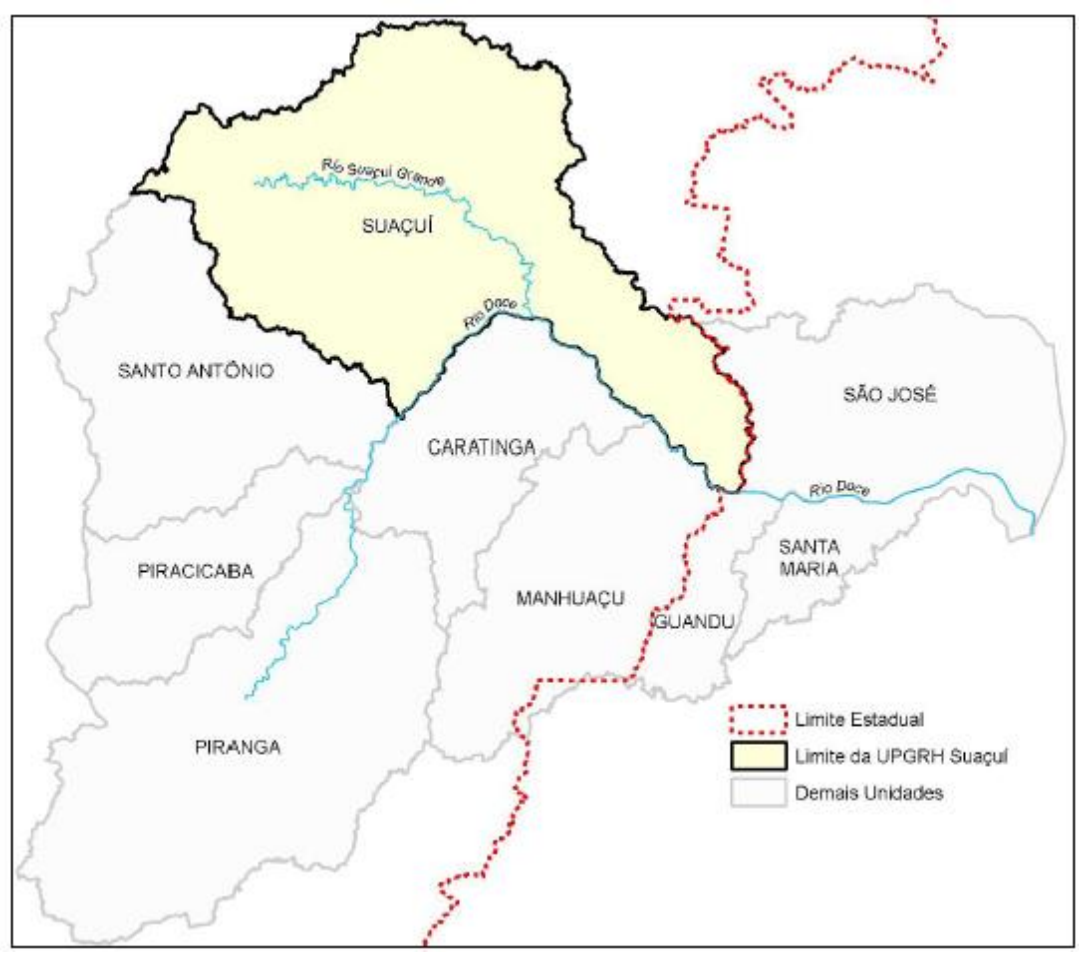

Fonte: Consórcio ECOPLAN - LUME, 2010.

A CH DO4 é composta pelas bacias hidrográficas do rio Suaçuí Grande, com área de $12.413 \mathrm{~km}^{2}$; do rio Suaçuí Pequeno $\left(1.720 \mathrm{~km}^{2}\right)$; e pela bacia do rio Corrente Grande, com área de $2.478 \mathrm{~km}^{2}$. Além destas, a área da CH DO4 possui uma área incremental, formada por áreas de drenagem de outros córregos que contribuem com menos representativa e drenam diretamente para o rio Doce, pela sua margem esquerda. A área incremental Suaçuí (DO4) possui área corresponde a 4.945 $\mathrm{km}^{2}$ (Consórcio ECOPLAN - LUME, 2010).

A CH DO4 é uma das áreas mais problemáticas em relação à suscetibilidade à erosão na bacia hidrográfica do rio 
Doce, apresentando $27 \%$ de sua área na classe de suscetibilidade média, $55 \%$ forte e $18 \%$ na classe muito forte (Consórcio ECOPLAN - LUME, 2010).

O território da referida bacia hidrográfica possui vocação predominantemente agropecuarista, com alta demanda de água para irrigação, além do consumo humano. Há predominância do uso pecuária (cerca de 67\%), principalmente no baixo curso dos rios Suaçuí Grande e Itambacuri, sendo cerca de 25\% da área da CH DO4 ocupada pelo ecossistema da Floresta Estacional Semi-Decidual (Consórcio ECOPLAN - LUME, 2010).

\subsection{Procedimentos metodológicos}

A metodologia aplicada neste trabalho, de forma a cumprir os objetivos propostos, foi adaptada do manual intitulado "Metodologia para Elaboração do Zoneamento Ambiental Produtivo (ZAP)", $3^{\mathrm{a}}$ edição SEMAD/SEAPA-MG (Faria et al., 2016), sendo, basicamente, a análise da demanda versus disponibilidade hídrica da bacia hidrográfica em estudo.

A demanda hídrica de uma bacia, ou seja, os usos consuntivos nela existentes, são conhecidos por meio do banco de dados das outorgas e cadastros de usos insignificantes de captação concedidas pelo órgão ambiental competente, neste caso, no Estado de Minas Gerais, o Igam. Dessa forma, estes dados foram coletados junto à Infraestrutura de Dados Espaciais do Sistema Estadual de Meio Ambiente e Recursos Hídricos - IDE-SISEMA, na data de 28 de setembro de 2020. Também no IDE-SISEMA foram obtidos shapes da rede hidrográfica estadual e das circunscrições hidrográficas

Os dados de outorgas e usos insignificantes foram coletados em formato de planilha Excel e geoespacializados em formato shape, sendo um arquivo Excel e um arquivo shape para as outorgas válidas na data do download, que possuem diferentes prazos de validade, a depender do tipo de uso do recurso hídrico, variando de 5 a 35 anos, assim como para os cadastros de usos insignificantes, que tem prazo de validade fixo, 3 anos para todos os casos.

Entre os dados disponibilizados, têm-se o número do processo, coordenadas geográficas, portaria, ano da portaria, vazão de captação, curso d'água, $\mathrm{CH}$, finalidade, modelo de uso, tipo, data de publicação e validade.

Para o processamento dos dados dos usuários de água da bacia, foram utilizados os softwares Excel e ArcGis 10.0. A partir dos dados brutos, foram aplicadas diversas seleções por atributos, no ArcGis, de forma a filtrar os dados específicos a serem usados na pesquisa.

Assim, primeiramente, foram selecionados os usuários que fazem captação superficial, excluindo das análises as captações subterrâneas. Selecionou-se também, os usuários considerando o status do processo como outorga deferida, renovada, retificada e cadastro efetivado (uso insignificante). Os demais foram retirados, uma vez que se tratava de outorga arquivada, cancelada, indeferida, vencida ou outros. Os dados analisados se referem, então, às portarias de outorgas e cadastros de usos insignificantes emitidos e disponibilizados no IDE-SISEMA até a data de 28 de setembro de 2020, ou seja, todos os usos de recursos hídricos na bacia regularizados e dentro da validade, nesta data.

Em seguida, foram excluídos os usuários de acordo com o modo de uso da água, como por exemplo, canalização/retificação de curso d'água, barramento em curso d'água sem captação, travessia rodoferroviária, dragagem, limpeza e desassoreamento de curso d'água, uma vez que são usos não consuntivos, que não interferem na disponibilidade hídrica quantitativa.

De posse dos cadastros de usuários, o próximo passo foi consistir os dados, verificando a ocorrência de processos repetidos. Verificou-se a vazão de captação de cada processo nas portarias de outorga por meio do website da SEMAD, principalmente em relação à unidade de medida $\mathrm{L} / \mathrm{s}$ ou m³/s, e todos os valores foram transformados $\mathrm{em} \mathrm{m} / \mathrm{s}$. Considerou-se a vazão do mês de setembro, por ser o mês fim do ano hidrológico, portanto marcando a transição entre o período seco e chuvoso, quando todos os usuários realizavam a captação (alguns não captam no período chuvoso).

Para a análise da disponibilidade hídrica nos trechos que possuem usuários outorgados, a vazão de referência $\left(\mathrm{Q}_{7,10}\right)$ 
foi obtida de acordo com os dados do Estudo de Regionalização de Vazão para o Aprimoramento do Processo de Outorga no Estado de Minas Gerais (Igam, 2012), desenvolvido pela Universidade Federal de Viçosa (UFV) e Igam e disponibilizado no website do IDE-Sisema. Foi feito o download do shape "rede hidrográfica", o qual continha os valores de $\mathrm{Q}_{7,10}$ de cada um dos trechos, dentre outros atributos, como "vazão média de longo termo".

Na CH DO4 o limite máximo de captações a serem outorgadas, por cada seção considerada em condições naturais é de 50\% da $\mathrm{Q}_{7,10}$, conforme Portaria Igam n ${ }^{\circ}$ 48, de 04 de outubro de 2019.

As demandas pelo uso da água em cada trecho foram obtidas por meio do ArcGis, utilizando a ferramenta "Buffer" com extensão de $200 \mathrm{~m}$ ao redor de cada trecho da rede hidrográfica, de modo que, no interior do polígono gerado estivessem todos os pontos das outorgas, relacionando-os aos respectivos trechos. Esse procedimento foi necessário tendo em vista que os pontos de outorgas plotados não necessariamente coincidem, fisicamente, com a linha do trecho de curso d'água. Foi realizada uma análise manual no intuito de observar se todos os usos de recursos hídricos foram incluídos no buffer gerado.

A partir desse procedimento, foi usada a ferramenta "Intersect" entre as camadas do buffer gerado anteriormente e as camadas contendo os usos outorgados. Assim, foi gerada uma nova camada, obtendo uma tabela de atributos com os dados das vazões outorgadas existentes em cada trecho, e a respectiva $Q_{7,10}$. Essa tabela foi exportada para a planilha Excel, onde foram criadas as colunas "QDO" (vazão de demanda hídrica outorgada) e " $\mathrm{Q}_{7,10}$ ". Os dados dessa planilha foram consistidos manualmente de forma a agrupar os dados de trechos com mais de um uso de recurso hídrico, somando todas as vazões existentes em cada trecho eliminando vazões replicadas em buffer de trecho vizinho.

O mesmo procedimento foi realizado com o shape dos cadastros de usos insignificantes, sendo então inserida na planilha Excel a coluna “QDUI” (vazões de demanda hídrica de usos insignificantes).

A vazão de disponibilidade hídrica (QDH) em cada trecho que possui demanda pelo uso da água foi determinada por meio da Equação 1.

$$
\mathrm{QDH}=0.5 * \mathrm{Q}_{7,10}-\mathrm{QDO}
$$

onde:

QDH: vazão de disponibilidade hídrica;

QDO: vazão de demanda hídrica outorgada.

Deste modo, adicionou-se uma nova coluna intitulada de "QDH". Nessa coluna foi feito o cálculo da disponibilidade hídrica de cada trecho, considerando a retirada das vazões outorgadas, por meio da expressão citada anteriormente.

Após ser realizada a análise do impacto na disponibilidade hídrica das vazões nos trechos nos quais existem outorgas e o impacto adicional nestes trechos das vazões de usos insignificantes, analisou-se a disponibilidade hídrica de todos os demais trechos de cursos d'água da CH DO4, nos quais existam usos insignificantes de água cadastrados (QDHUI), por meio da Equação 2.

$$
\mathrm{QDHUI}=0.5 * \mathrm{Q}_{7,10}-\mathrm{QDTUI}
$$

em que,

QDHUI: vazão de disponibilidade hídrica de trechos com usos insignificantes;

QDTUI: vazão de demanda total de usos insignificantes.

Por fim, para determinar o grau de impacto das captações superficiais analisadas, criou-se o Índice de Disponibilidade Hídrica (IDH), considerando QDO (vazão de demanda hídrica outorgada), QDT (vazões de demanda hídrica total) e QDTUI (vazão de demanda total de usos insignificantes). As seguintes situações foram analisadas para QDO, com semelhança na QDT e QDTUI: 
Se QDO/0.5* $\mathrm{Q}_{7,10}<50 \%$ : Disponibilidade;

Se $50 \% \leq \mathrm{QDO} / 0.5^{*} \mathrm{Q}_{7,10}<100 \%$ : Atenção; ou

Se QDO/0.5* $\mathrm{Q}_{7,10} \geq 100 \%$ : Indisponibilidade.

\section{Resultados e Discussão}

$\mathrm{Na}$ data da coleta dos dados (28 de setembro de 2020), existiam 1098 cadastros de usos insignificantes e 118 pontos de outorga de uso da água, totalizando 1216 captações superficiais regularizadas e válidas na circunscrição hidrográfica do rio Suaçuí, com demanda de 5,28 m³/s. Destes, 4,45 m³/s são referentes às vazões outorgadas $(84,28 \%)$ e $0,83 \mathrm{~m}^{3} / \mathrm{s}$ referentes aos usos insignificantes $(15,72 \%)$. Os resultados estão apresentados na Figura 2.

Figura 2 - Captações superficiais em corpo de água na bacia do rio Suaçuí.

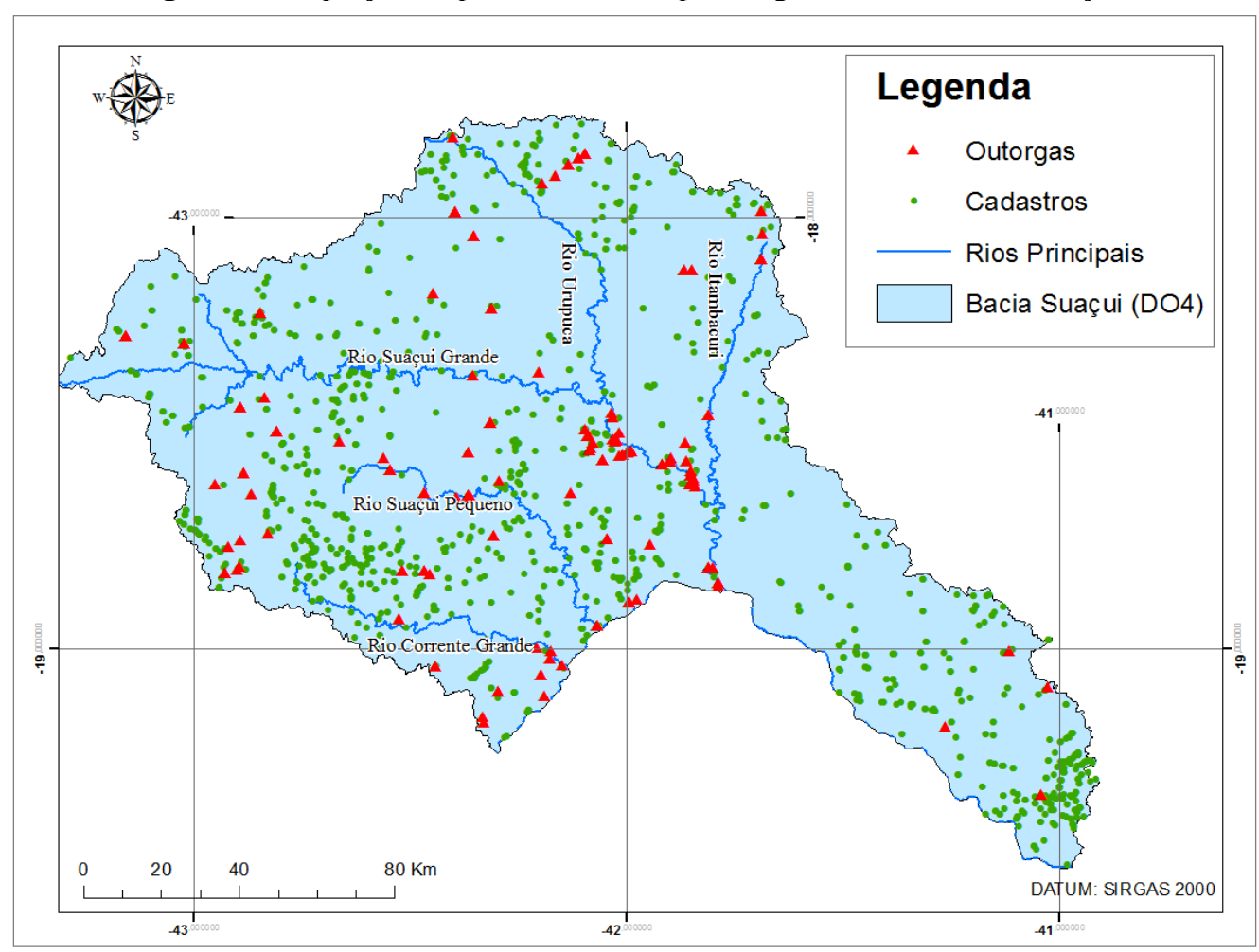

Fonte: Autores (2021).

A irrigação é o tipo de uso consuntivo da água predominante na área de estudo, com percentual de $44 \%$ da vazão consumida, que se deve à vocação agropecuarista local. O uso é seguido pelo abastecimento público (29\%) e aspersão de vias (14\%). Com menor representatividade há o consumo agroindustrial, a dessedentação animal e a extração mineral.

De acordo com a ANA (2019), o inventário de cadastros e outorgas de uso da água é útil para diversas aplicações, mas também não garante precisão quanto aos volumes efetivamente utilizados, uma vez que o valor outorgado tende a um limite máximo de abastecimento, como exemplos, uma indústria que opera em capacidade instalada máxima (100\%) ou um município que atenderá sua crescente população em cenário futuro. Logo, as vazões médias efetivas possuem tendência de serem inferiores, em especial para os usuários com alto consumo.

Por outro lado, existem usuários de água na bacia hidrográfica do rio Suaçuí que captam o recurso hídrico sem a devida outorga ou cadastro de uso insignificante, de forma irregular, e assim não estão sendo contabilizados oficialmente, conforme evidencia o estudo feito por Moreira et al. (2020), no qual avaliou-se fiscalizações em recursos hídricos realizadas pelo órgão ambiental de Minas Gerais. Neste estudo, os resultados apontaram que 18,75\% dos usuários fiscalizados foram 
autuados por captar água superficial sem a devida outorga e 18,75\% dos usuários fiscalizados foram autuados por utilizar recursos hídricos, nos casos de usos insignificantes definidos, sem o respectivo cadastro.

A CH DO4 possui ao todo 35.278 trechos de cursos d'água. Segundo a metodologia aplicada neste trabalho (Igam, 2012), dos 118 usuários de águas superficiais na área de estudo, 25 fazem captação de água superficial em trecho classificado como "indisponibilidade", ou seja, a vazão de demanda outorgada (QDO) é superior à vazão mínima de referência. Essas captações resultam no total de 759 trechos em situação de indisponibilidade, considerando que todos os trechos à montante da captação também estão na mesma situação.

Outros 15 usuários captam água em trechos classificados como "atenção", resultando em 719 trechos em estado de atenção, ou seja, a QDO está entre 50 a 100\% da vazão mínima de referência, sugerindo uma gestão mais cautelosa em relação à disponibilidade hídrica.

E 78 usuários captam água em trechos que foram classificados como "disponibilidade", ou seja, a QDO é inferior a 50\% da vazão mínima de referência. Assim, os 33.800 trechos restantes se encontram em situação de disponibilidade, considerando também aqueles que não apresentam demanda outorgada.

A Figura 3 apresenta o mapa com a classificação dos trechos dos cursos d'água e o índice de disponibilidade hídrica. 
Figura 3 - Mapa com a classificação do índice de disponibilidade hídrica em trechos de cursos d'água com usuários outorgados (IDH_QDO).

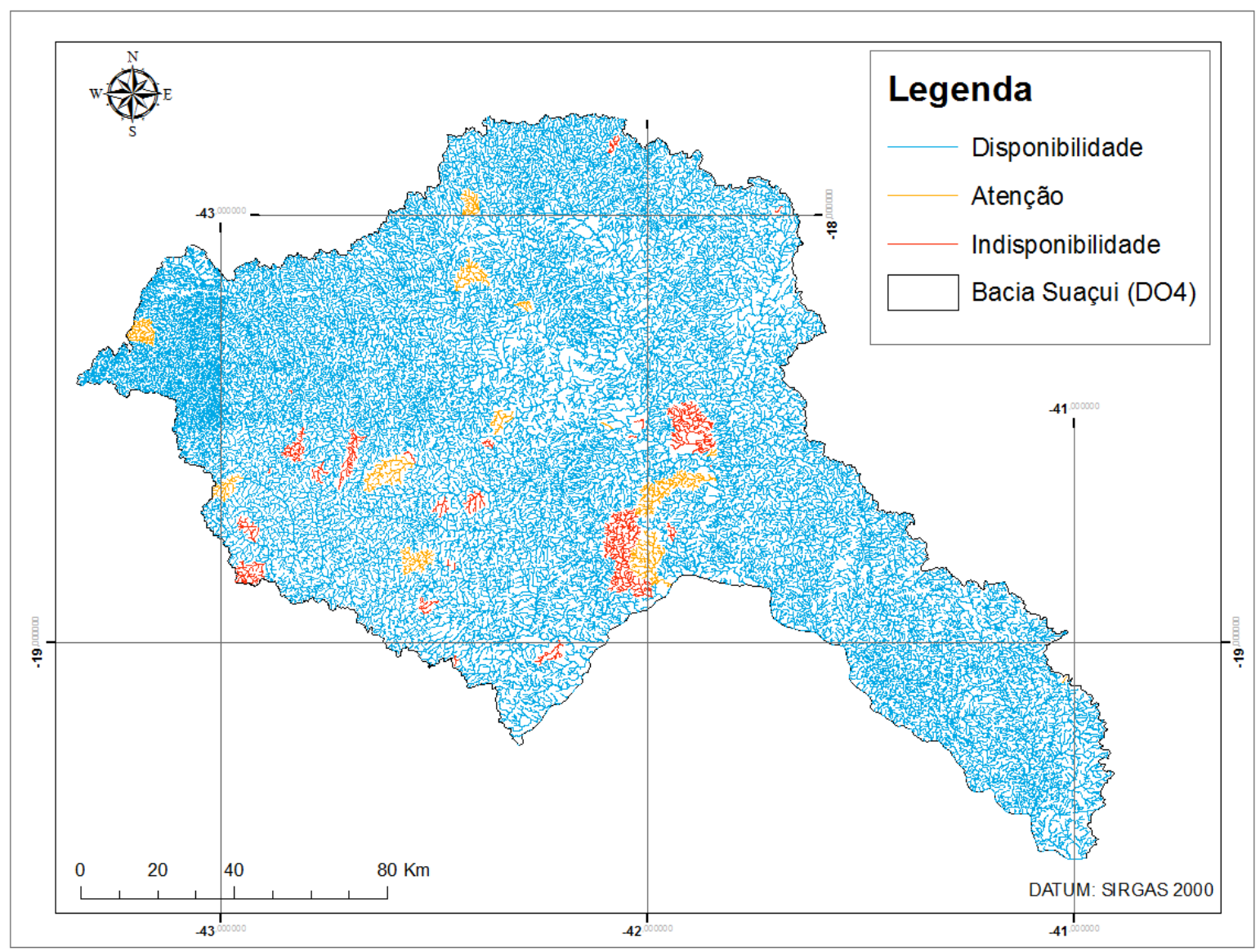

Fonte: Autores (2021).

Observou-se, portanto, que os usos outorgados geram interferências significativas na disponibilidade hídrica dos respectivos trechos de cursos d'água, mesmo desconsiderados os usos insignificantes neles existentes. Destaca-se que dos 25 usos outorgados instalados em trecho classificado como "indisponibilidade", $10(40 \%)$ tem como finalidade o uso na irrigação, 7 (28\%) no abastecimento público, 5 (20\%) para a aspersão de vias, $2(8 \%)$ ao consumo industrial e 1 (4\%) ao consumo humano.

Para avaliar o impacto dos usos insignificantes cadastrados na bacia hidrográfica, nos trechos que possuem captações outorgadas, realizou-se a comparação dos trechos com status diferentes entre as colunas "IDH_QDO" e "IDH_QDT", com o intuito de identificar trechos com outorgas que tiveram a disponibilidade hídrica alterada após a inserção das vazões de usos insignificantes (QDT).

A comparação não resultou em alterações, sendo então o IDH_QDT igual ao IDH_QDO para todos os trechos, ou seja, o IDH_QDT ficou como "disponibilidade" em 78 (66\%) dos usuários. Outros 15 (13\%) usuários captam água em trechos classificados como "atenção", resultando num total de 719 trechos em estado de "atenção", e 25 (21\%) fazem captação de água superficial em trecho classificado como "Indisponibilidade", resultando num total de 759 trechos em situação de indisponibilidade, conforme figura anterior.

No entanto, 4 dos trechos nos quais houve a inserção de vazões de usos insignificantes, se encontravam com IDH_QDO "indisponibilidade", sendo evidente que, com o acréscimo das vazões retiradas, a situação da disponibilidade hídrica se agrava. 
Verificou-se a disponibilidade hídrica em todos os trechos da bacia hidrográfica que possuem usuários insignificantes. Os usuários insignificantes de água existentes na $\mathrm{CH}$ DO4, até a data de coleta dos dados, somavam 1098, captando vazões de águas superficiais iguais ou inferiores a 1,0 L/s.

Segundo a metodologia aplicada neste estudo (Igam, 2012), dos 1098 usuários de águas superficiais na CH DO4, 555 fazem captação de água superficial em trecho classificado como "Indisponibilidade", ou seja, a vazão de demanda total de usos insignificantes (QDTUI) é superior à vazão mínima de referência do trecho, resultando num total de 776 trechos em situação de indisponibilidade, considerando que todos os trechos à montante da captação também são considerados na mesma situação.

Outros 119 usuários captam água em trechos classificados como "atenção", resultando num total de 467 trechos em estado de atenção, ou seja, a QDUI está entre 50 a 100\% da vazão mínima de referência, sugerindo que ocorra uma gestão mais cautelosa em relação à disponibilidade hídrica superficial na área. Nesses casos, verificou-se que a inserção de um ou mais usuários no trecho pode levá-lo à situação de indisponibilidade.

E 424 usuários captam água em trechos que foram classificados como "disponibilidade", ou seja, a QDTUI é inferior a $50 \%$ da vazão mínima de referência. Assim, os 34.604 trechos restantes se encontram em situação de disponibilidade, considerando também aqueles que não apresentam demanda de usos insignificantes.

$\mathrm{Na}$ figura a seguir são apresentados os trechos de cursos d'água com usuários insignificante e a classificação quanto ao índice de disponibilidade hídrica.

Figura 4 - Mapa com a classificação do índice de disponibilidade hídrica nos trechos de cursos d'água com usuários insignificantes (IDH_QDTUI).

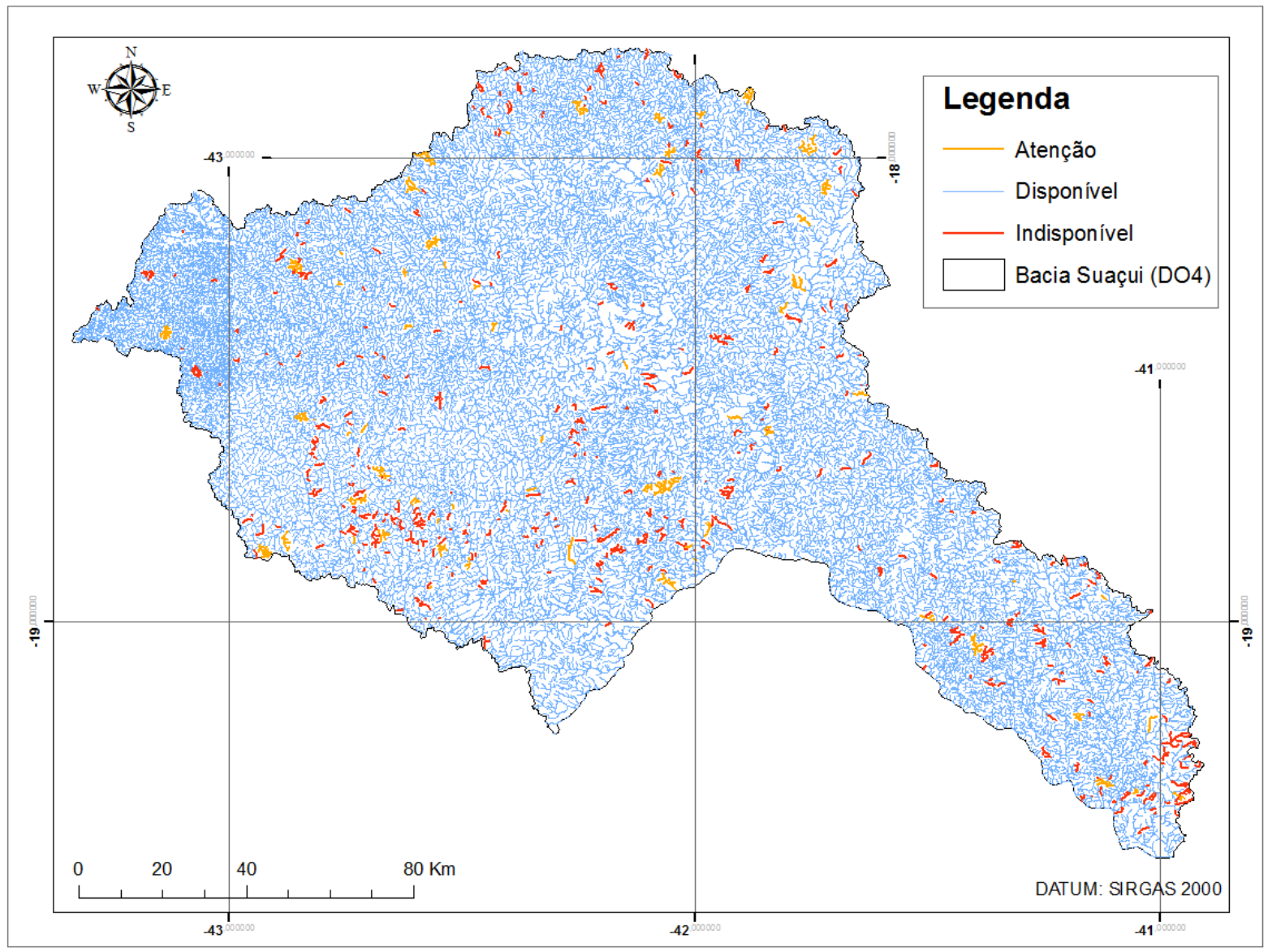

Fonte: Autores (2021). 
A bacia hidrográfica do rio Suaçuí é composta de 35.278 trechos de cursos d'água, os quais são identificados com um ottocódigo na base de dados obtida. Destes, 1199 apresentam demanda pelo uso de recursos hídricos (outorgas e usos insignificantes de água).

As análises realizadas considerando cada trecho de curso d'água que apresenta demanda pelo uso da água, seja outorgado ou cadastrado como uso insignificante, revelaram um cenário de relativa indisponibilidade, principalmente considerando os usos insignificantes, quando esta situação foi majoritária.

Observou-se, de acordo com os resultados encontrados, que grande parte dos trechos com demandas de usos insignificantes em situação de "indisponibilidade" se encontram em trechos de pequena extensão e em cabeceiras de bacia. Estes trechos normalmente apresentam baixas vazões e, consequentemente, as vazões mínimas de referência ainda mais reduzidas, afetando drasticamente a disponibilidade hídrica dos mesmos. Além disso, as captações insignificantes existentes nestes trechos têm como finalidade de uso a irrigação, o consumo humano e a dessedentação de animais, que juntos representam $79 \%$ dos usuários.

Ainda, foi observado que a presença de duas ou mais captações consideradas insignificantes em um trecho, ou em trechos consecutivos, também representa boa parte dos trechos em situação de indisponibilidade. Como exemplo, no Ribeirão Santo Antônio, localizado na zona rural do município de Itueta-MG, existem 11 captações inferiores a 1,0 L/s (Figura 5), mas que ao todo somam a vazão de $0,0088 \mathrm{~m} 3 / \mathrm{s}(8,8 \mathrm{~L} / \mathrm{s})$, ao passo que a vazão mínima de referência no trecho da captação mais a jusante é de $0,0014 \mathrm{~m}^{3} / \mathrm{s}(1,4 \mathrm{~L} / \mathrm{s})$, portanto, mais de 6 vezes menor que vazão captada.

Figura 5 - Zoom esquemático no Ribeirão Santo Antônio, evidenciando os usos insignificantes existentes.

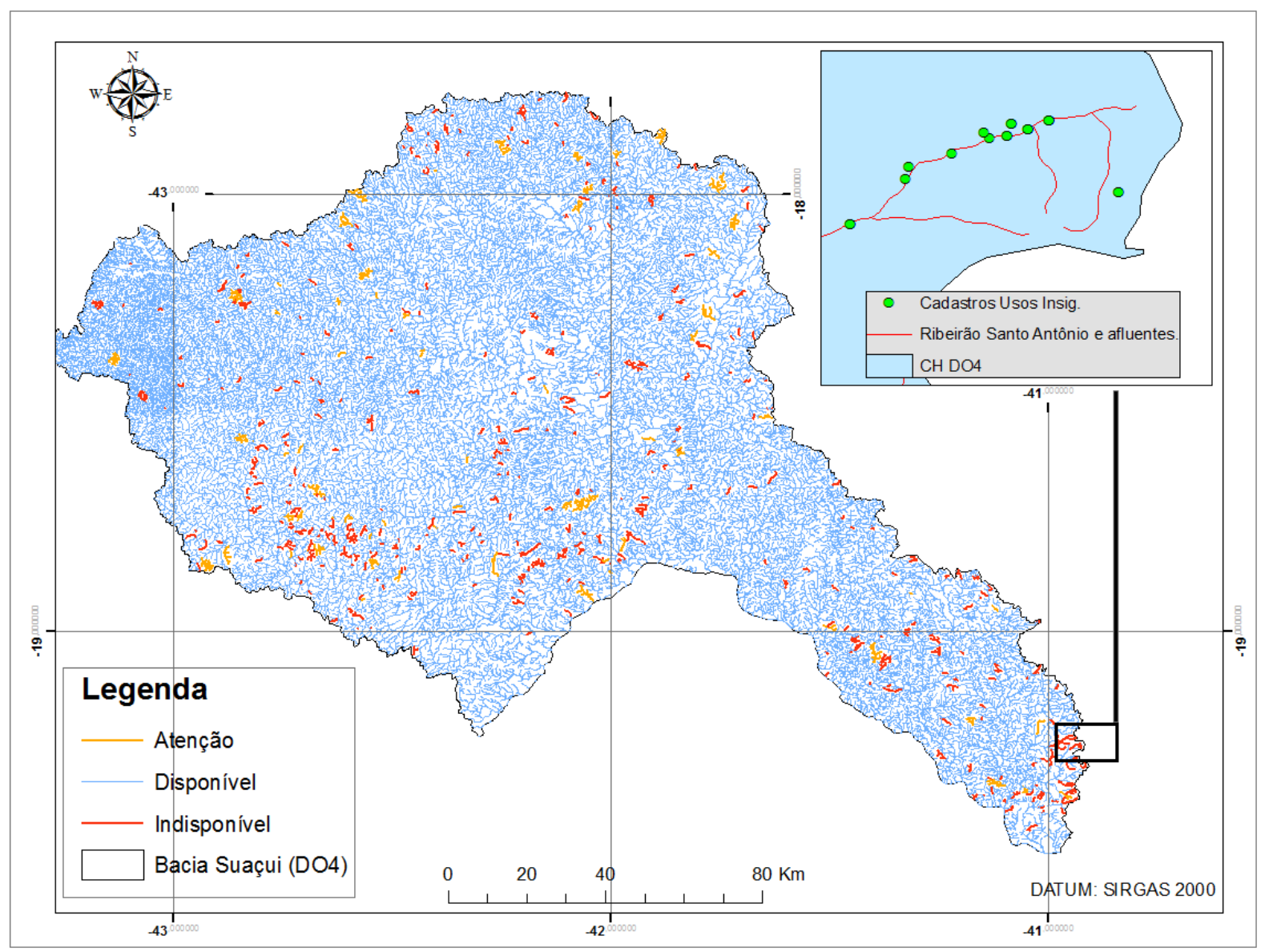

Fonte: Autores (2021).

Os resultados apontam que os usos insignificantes existentes na CH DO4 são capazes de gerar interferências negativas 
na disponibilidade hídrica de sub-bacias, principalmente as localizadas em regiões de cabeceira, mais à montante. Provam, ainda, que um conjunto de usos insignificantes em determinados trechos podem diminuir substancialmente a disponibilidade hídrica, fator que pode desencadear impactos significativos nos recursos hídricos, principalmente no que se refere à manutenção das vazões mínimas ou ecológicas, necessárias à garantia da manutenção dos ecossistemas aquáticos.

Portanto, fica evidente que a forma como são concedidos os cadastros de usos insignificantes deve ser revista, tomando como base a disponibilidade hídrica do trecho a ser demandado, e não apenas limitado por uma vazão máxima genérica. Nesta hipótese, provavelmente, em alguns casos, não haverá disponibilidade hídrica para todos os usos pretendidos, uma vez que poderá ser menor que a demanda dos usuários.

Alternativas podem ser adotadas, neste caso, como a construção de pequenos barramentos em curso de água com regularização de vazão. Ribeiro et al. (2018) analisaram as variações na disponibilidade hídrica ocasionadas pela consideração da vazão permissível de outorga para condições de regularização em relação ao critério a fio d'água, sendo para isso apresentado um estudo de caso para a bacia hidrográfica do rio Paracatu. Para isso, foi estimada, para cada trecho da hidrografia, a relação $\mathrm{Q}_{\mathrm{mld}} / \mathrm{Q}_{7,10} \mathrm{e}$ a diferença percentual entre os critérios utilizados no estado para concessão de outorga com e sem a presença de estruturas de regularização. Os valores obtidos para a relação $Q_{\text {mld }} / Q_{7,10}$ variaram de 3,7 a 10,0 , e o incremento de disponibilidade de 531 a 1795\%, resultado que reforça a potencialidade dos reservatórios no aproveitamento do uso da água. Outra alternativa é a oferta de águas subterrâneas, em poços manuais (cisternas) e poços tubulares.

Contudo, é sabido que a bacia hidrográfica do rio Suaçuí Grande tem sido castigada pelos efeitos da seca, nos períodos de estiagem, chegando a ter vazões diárias de 7 dias consecutivos observadas na estação fluviométrica "Vila Matias Montante" inferiores a 50\% da $\mathrm{Q}_{7,10}$, conforme declarações de situação crítica de escassez hídrica, pelo Igam, nos últimos anos, conforme Portarias Igam n 36/2015, 38/2017, 23/2018, 25/2019 e, a mais recente, Portaria Igam ${ }^{\circ} 43$, de 11 de junho de 2021.

Nesse sentido, a diminuição das vazões médias na circunscrição hidrográfica do rio Suaçuí também é fator que contribui para o comprometimento da disponibilidade hídrica desta porção hidrográfica e deve ser avaliada na tomada de decisões na gestão dos recursos hídricos da área estudada.

\section{Conclusão}

O diagnóstico da disponibilidade hídrica da bacia hidrográfica do rio Suaçuí (CH DO4) permite, além de identificar a interferência dos usos insignificantes de água, principal objetivo desta pesquisa, fornecer subsídios para a gestão integrada dos aspectos quantitativos dos recursos hídricos, em nível de bacia hidrográfica, ao ser realizada a estimativa da disponibilidade hídrica e identificação dos trechos dos cursos d'água comprometidos e em situação de indisponibilidade.

Quando feita a análise da disponibilidade hídrica por cada trecho de curso d'água da $\mathrm{CH}$ DO4, em relação às vazões outorgadas, foram identificados 759 trechos em situação de indisponibilidade hídrica, causados por 25 captações outorgadas, equivalente a $21 \%$ dos usos outorgados.

Ao analisar a situação da disponibilidade hídrica na $\mathrm{CH}$ DO4 em todos os trechos de cursos d'água com usos insignificantes cadastrados, foram identificados 776 trechos em situação de indisponibilidade hídrica, causados por 555 captações de usos insignificantes, o que corresponde a 50\% dos usuários considerados insignificantes. Grande parte destes usos se encontram em trechos de pequena extensão e em cabeceiras de bacia, os quais apresentam baixas vazões e, consequentemente, as vazões mínimas de referência ainda mais reduzidas, afetando drasticamente a disponibilidade hídrica dos mesmos.

A presença de duas ou mais captações consideradas insignificantes em um trecho, ou em trechos consecutivos, também representou boa parte dos trechos em situação de indisponibilidade hídrica. Desse modo, pode-se concluir que um 
conjunto de usos insignificantes em determinados trechos pode diminuir substancialmente a disponibilidade hídrica, fator que pode desencadear impactos significativos nos recursos hídricos, principalmente no que se refere à manutenção das vazões mínimas ou ecológicas, necessárias à garantia da manutenção dos ecossistemas aquáticos.

Além da demanda pela água na $\mathrm{CH} \mathrm{DO} 4$, outro fator que contribui para o comprometimento da disponibilidade hídrica da porção hidrográfica é a tendência de queda das vazões médias mensais na bacia hidrográfica.

Portanto, diante dos resultados, conclui-se que os usos insignificantes de água são capazes de interferir sistematicamente na disponibilidade hídrica de uma bacia hidrográfica, principalmente em Minas Gerais, considerando sua regulamentação atual para regularização destes usos.

Emerge a necessidade de atualização da Política Estadual de Recursos Hídricos de Minas Gerais, nesse sentido, visando a preservação do ecossistema aquático e uma alocação das águas mais realista. Para tanto, recomenda-se que eventual nova metodologia de emissão de cadastros de usos insignificantes no Estado de Minas Gerais tenha como referência a disponibilidade hídrica do trecho a ser demandado, seguindo os critérios da vazão de referência. Além disso, é fundamental que a regularização destes usos leve em consideração todos os usuários existentes no trecho, de forma a obter um balanço hídrico real.

\section{Referências}

ANA - Agência Nacional de Águas e Saneamento Básico. (2019). Manual de Usos Consuntivos da Água no Brasil. http://www.snirh.gov.br/portal/snirh/centrais-de-conteudos/central-de publicacoes/ana_manual_de_usos_consuntivos_da_agua_no_brasil.pdf.

Brasil. (1997). Lei Federal $n^{\circ}$ 9.433, de 8 de janeiro de 1997. Institui a Política Nacional de Recursos Hídricos, cria o Sistema Nacional de Gerenciamento de Recursos Hídricos, regulamenta o inciso XIX do art. 21 da Constituição Federal, e altera o art. $1^{\circ}$ da Lei ${ }^{\circ} 8.001$.

Carrera-Fernandez, J. \& Garrido, J. R. (2002). Economia dos recursos hídricos: EdUFBA.

Castro, M. M., Maia, J. L., Silva, J. P. O. \& Vieira, E. M. (2021). Análise da disponibilidade hídrica superficial na bacia hidrográfica do rio Piracicaba - MG. Research, Society and Development, 10 (3), e42610313552. https://rsdjournal.org/index.php/rsd/article/view/13552.

CERH - Conselho Estadual de Recursos Hídricos. (2004). Deliberação Normativa do Conselho Estadual de Recursos Hídricos - MG $n^{\circ} 09$, de 16 de junho de 2004. Define os usos insignificantes para as circunscrições hidrográficas no Estado de Minas Gerais.

Consórcio Ecoplan - Lume. (2010). Plano de Ação de Recursos Hídricos da Unidade de Planejamento e Gestão dos Recursos Hídricos Suaçuí. https://www.cbhdoce.org.br//wp-content/uploads/2016/12/PARH_Suacui.pdf.

Cruz, J. C. (2001). Disponibilidade hídrica para outorga: avaliação dos aspectos técnicos e conceituais. Tese de Doutorado, Universidade Federal do Rio Grande do Sul, Porto Alegre, RS.

Duarte, V. A. \& Miola, D. T. B. (2016). Análise de disponibilidade hídrica na microbacia do Ribeirão Paciência: relação entre a oferta e o volume de água outorgado em Pará de Minas. Revista Digital FAPAM. 7 (7), 32-54.

Faria, L.V, Brito, G. C. B., Cagna, C. E. \& Leão, G. O. (2016). Metodologia do Zoneamento Ambiental Produtivo - ZAP de sub-bacias hidrográfica.

Igam - Instituto Mineiro de Gestão das Águas. (2012). Estudo de Regionalização de Vazão para o Aprimoramento do Processo de Outorga no Estado de Minas Gerais.

Igam - Instituto Mineiro de Gestão das Águas. (2015). Portaria n ${ }^{o} 36$ de 03 de Dezembro de 2015. Declara Situação Crítica de Escassez Hídrica Superficial na porção hidrográfica localizada a montante da estação Vila Matias e a sua bacia de contribuição. http://www.siam.mg.gov.br/sla/download.pdf?idNorma=39536.

Igam - Instituto Mineiro de Gestão das Águas. (2017). Portaria n ${ }^{\circ} 38$ de 25 de Julho de 2017. Declara Situação Crítica de Escassez Hídrica Superficial na porção hidrográfica localizada a montante da estação Vila Matias e a sua bacia de contribuição. http://www.siam.mg.gov.br/sla/download.pdf?idNorma=44790.

Igam - Instituto Mineiro de Gestão das Águas. (2018). Portaria $n^{o} 23$ de 13 de agosto de 2018. Declara Situação Crítica de Escassez Hídrica Superficial na porção hidrográfica localizada a montante da estação Vila Matias e a sua bacia de contribuição. http://www.siam.mg.gov.br/sla/download.pdf?idNorma=46430.

Igam - Instituto Mineiro de Gestão das Águas. (2019). Portaria $n^{\circ} 48$ de 04 de Outubro de 2019. Estabelece normas suplementares para a regularização dos recursos hídricos de domínio do Estado de Minas Gerais e dá outras providências. http://www.siam.mg.gov.br/sla/download.pdf?idNorma=49719.

Igam - Instituto Mineiro de Gestão das Águas. (2021). Portaria no 43 de 11 de Junho de 2021. Declara Situação Crítica de Escassez Hídrica Superficial na porção hidrográfica localizada a montante da estação São Pedro do Suaçuí e a sua bacia de contribuição. http://www.siam.mg.gov.br/sla/download.pdf?idNorma=53947. 
Levy, B. S. \& Sidel, V. W. (2011). Water rights and water fights: preventing and resolving conflicts before they boil over. Am J Public Health, 101 (5), 778 780.

Marcolini, F. C. P. (2016). A influência das captações de águas superficiais consideradas insignificantes na vazão do Ribeirão Água Fria, Palmas - TO. Dissertação de Mestrado, Universidade Federal do Tocantins, Palmas, TO.

Medeiros, M. J. (2000). Avaliação da vazão referencial como critério de outorga dos direitos de usos das águas na bacia do Paraopeba. Dissertação de Mestrado, Universidade Federal de Minas Gerais, Belo Horizonte, MG.

Mendes, L. A. (2007). Análise dos critérios de outorga de direito de usos consuntivos dos recursos hídricos baseados em vazões mínimas e em vazões de permanência. Dissertação de Mestrado, Universidade de São Paulo, São Paulo, SP.

Minas Gerais. (1999). Lei Estadual $n^{\circ}$ 13.999, de 29 de Janeiro de 1999. Política Estadual De Recursos Hídricos e dá outras providências. https://www.almg.gov.br/consulte/legislacao/completa/completa.html?num=13199\&ano=1999\&tipo=LEI.

Minas Gerais. (2001). Decreto Estadual n 41.578, de 8 de março de 2001. Regulamenta a Lei Estadual n 13.199/1999.

Moreira, G. B., Andrade, C. B. S. \& Gonçalves, J. A. C. (2020). A fiscalização do uso outorgado dos recursos hídricos de bacia declarada em situação crítica de escassez hídrica: estudo de caso na bacia Rio Suaçuí - MG. Research, Society and Development, 9 (7), e81973729. https://www.rsdjournal.org/index.php/rsd/article/view/3729.

Moreira, M. C., Silva, D. D., Pruski, F. F. \& Lara, M. S. (2012). Índices para Identificação de Conflitos pelo Uso da Água: Proposição Metodológica e Estudo de Caso. Revista Brasileira de Recursos Hídricos, 7 (3), 7-15.

Pereira A. S., Shitsuka, D. M., Pereira, F. J. \& Shitsuka, R. (2018). Metodologia da pesquisa científica. https://repositorio.ufsm.br/bitstream/handle/1/15824/Lic_Computacao_Metodologia-Pesquisa-Cientifica.pdf?sequence=1.

Ribeiro, R. B., Pruski, F. F. \& Ramos, M. C. A. (2018). Disponibilidade hídrica em condições de regularização de vazão. Sustentare, 2 (2), $210-217$. http://periodicos.unincor.br/index.php/sustentare/article/view/5117.

Salis, H. C. (2017). Diagnóstico da disponibilidade hídrica na bacia hidrográfica do rio Manso-MG. Caminhos de Geografia, 18 (64), 91-102. http://www.seer.ufu.br/index.php/caminhosdegeografia/article/view/40914.

Secretaria de Estado do Meio Ambiente e Recursos Hídricos. (2004). Resolução SEMA nº 039, de 26 de Novembro de 2004.

SEMAD - Secretaria de Estado de Meio Ambiente e Desenvolvimento Sustentável. (2019). Fiscalização Ambiental 2019 - Relatório de Atividades.

Silva, B. M. B., Silva, D. D. \& Moreira, M. C. (2015). Índices para a Gestão e Planejamento de Recursos Hídricos na Bacia do Rio Paraopeba, Estado de Minas Gerais. Revista Ambiente e Água, 10 (3), 685-697. http://www.scielo.br/pdf/ambiagua/v10n3/1980-993X-ambiagua-10-03-00685.pdf.

Silva, L. M. C. \& Monteiro, R. A. (2003). Outorga de direito de uso de recursos hídricos: uma das possíveis abordagens. Interciência, 1, 140-179.

Stinghen, C. M. \& Mannich, M. (2019). Diagnóstico de outorgas de captação e lançamento de efluentes no Paraná e impactos dos usos insignificantes. Revista de Gestão de Água da América Latina, 16 (10).

Vilar, P. C. (2014). Governança da Água na América Latina. Material didático do curso à distância Governança da Água na América Latina: Fundação Parque Tecnológico Itaipu. 